\title{
HAND-TO-HAND COMBAT WITH OR WITHOUT PORTABLE ARMAMENT - FUNDAMENTAL ELEMENTS FOR THE TRAINING OF THE MODERN MILITARY
}

\author{
Lt.Col.Sup.Instr. George-Florin BĂIŢAN, PhD*
}

\begin{abstract}
Despite technological advances, hand-to-hand combat with or without portable armament remains a necessity in the contemporary operating environment, especially given the ambiguity of urban warfare and the close and regular interaction of the military with various adversaries (combatants or non-combatants) a wide range of situations in which force is used. Being a commitment between two or more people, in a confrontation in which ammunition is not used; training the military on hand-to-hand combat seems an important component that the military must consider in the physical preparation of the military for future conflicts. Cultivating courage to increase self-confidence is one of the most important benefits that handto-hand combat training can have. In a tense situation, having trained fighting skills in this regard can mean the difference between opening fire and escalating conflict, on the one hand, and avoiding disputes through a self-control approach to the factors that cause pain and fear, on the other hand.
\end{abstract}

Keywords: hand-to-hand combat; portable weapons; technical procedures; specific training; physical training; military physical education.

Hand-to-hand combat consists of a physical confrontation, simultaneously between two or more soldiers, empty-handed or using portable weapons (without ammunition) or equipment such as: pistol/submachine gun, pistol, bayonet, shovel small infantry, etc. The training of motor skills in the military in this mixed form of martial arts must be one of the fundamental components of modern military training models. It is about the ability of a soldier to think about his next move, being aware of the conditions or environmental changes that have occurred and considering the procedure he could use against his opponent.

The military must be prepared to use different levels of force, given that the intensity of a conflict can only change in a few moments. Many military operations (such as peacekeeping missions or evacuation of non-combatant civilians or nonessential military personnel) will be carried out using intentionally fewer weapons and ammunition. In these situations, if an unexpected confrontation occurs, mastering hand-to-hand combat procedures with and without portable weapons can save the lives of the military, because the automation of these motor actions also helps to develop courage and

\footnotetext{
*"Ferdinand I" Military Technical Academy e-mail: baitan_george_florin@yahoo.com
}

self-confidence. With the formation of these skills comes the understanding of controlled aggression and the ability to stay focused during a constraint. The training program to strengthen the skills of hand-to-hand combat with an opponent will also include a harder component of specific physical training, which is, at the same time, both physically exhausting and mentally demanding. The general objectives of these types of training must include, in addition to educating the entire basic or specific motor qualities specific to self-defence, and building personal courage, self-confidence, self-discipline and "body spirit".

The training of the military to fight handto-hand, with or without the portable armament provided, is carried out in order to form action skills specific to the situations that arise during the fighting, as well as during the performance of independent combat missions the firearm of the individual weapon cannot be used.

\section{General aspects regarding the specific preparation for hand-to-hand combat} with or without the portable armament provided

A recent study found that the US military, which conducted missions to theaters of operations in Iraq and Afghanistan (between 2004 and 2008), reported $(19 \%)$ that they had used a technical process at least once, of hand-to-hand combat, in 
a variety of circumstances and contexts (during the handling of prisoners, crowd control or access to the base of people at the checkpoint, etc.). This supports previous research that has shown that, despite technological advances, hand-to-hand combat has remained a persistent aspect of modern warfare. $^{2}$

At the base of all self-defence techniques there are some essential elements, which any soldier must apply to defeat an opponent in hand-to-hand combat. Their progressive and systematic learning will instill in the military some fundamental aspects on which self-defence is based, such as:

- calm attitude and mental balance - during a fight a soldier must keep his ability to think lucidly and must not allow fear or anger to control his actions;

- situational awareness - things that often happen around the military that are involved in a hand-to-hand combat could have a direct impact on the end result of the fight. This principle refers to the efficient use of existing objects in the vicinity (so-called "weapons of opportunity"3) or to receiving possible helps from other soldiers joining the fight;

- suppleness technique - a soldier cannot rely on the assumption that he is bigger and stronger than his opponent. Therefore, he should never try to oppose the enemy by a direct attempt at force. The use of the opponent's force, by applying articulation techniques and dodges made by pivots, can be a way and a fighting strategy to overcome a superior force;

- support base - refers to the adoption of a stable body position, from which to move quickly in attack or defence (depending on the situation). In general, a military man must maintain the stability of his body by lowering his center of gravity and increasing his support base;

- dominant position of the body - refers to the positioning of the body of the fighting soldier in relation to his opponent. When fighting, before applying any technique to take the opponent out of battle, a vital principle is to gain and maintain control over the enemy by maintaining a dominant body position (especially in ground combat);

- optimal combat distance - each technical procedure has a distance from the opponent from which it must be initiated in order to have the highest efficiency, taking into account the time required to cross this space, the angle and pace of the attack ${ }^{4}$. To control the fight, the fighting soldier must control the distance between himself and the opponent;

- physical balance - refers to the ability of the military to maintain balance and remain in a stable upright position;

- joint techniques - a military fighter must use his body parts to create an advantage, using techniques aimed at blocking or twisting the opponent's limbs at the joints. Using joint levers, a soldier can reach a dominant position over an enemy with a much heavier body weight.

A specific training program for hand-to-hand combat with or without portable armament should be especially designed to train as many soldiers as possible, to become effective fighters, in the shortest possible time and in the safest way possible. In this regard, several general safety measures and precautions must be taken:

- technical combat procedures should be learned and strengthened in a certain order, gradually assimilated from simple to complex, and those considered more dangerous (as well as combinations) should be trained after the military has become familiar with the dynamics of general techniques. This will result in fewer serious injuries caused by more dynamic movements;

- the training of the military must always be carried out under the proper supervision of a qualified instructor, as the technical procedures involved have a potential danger;

- most workouts should be performed on a soft combat surface (such as a grassy or sandy area), thus reducing stress on the joints of the lower limbs (such as the ankles and knees);

- strangulation (suffocation by choke) is the best way to end a fight and the most effective way to immobilize an opponent in just a few seconds. These procedures are safe enough to apply to training just like on the battlefield;

- joint dislocations - to get an enemy out of battle, attacks must be directed against his larger joints (such as the elbow or shoulder). These joints are very painful long before their injury occurs, which allows the military to train by practicing technical procedures in conditions very close to the real ones, without a significant risk of injury. Exceptions are attacks on the wrist (which is very easily injured) and on the knee (twisting it becomes 
painful when it may be too late). Therefore, these attacks should be learned very carefully and should not be allowed in sports competitions, but rather used only in a real confrontation with an enemy;

- blows are those powerful and effective attacks carried out on the enemy, with part of the body or with the portable armament provided, in order to destroy him and capture his weapon. These are an important part of an overall fighting strategy and can be very effective in a confrontation, as it often puts the opponent in an unfavorable situation. During training, blows can be practiced using various protective equipment (helmets, bustiers, shins, vests, dental / genital protections, etc.) to ensure the prevention of serious injuries. Military training should continuously focus on situations that may arise in a real battle.

Vocational training is the key to success in training the military to fight hand-to-hand with or without portable weapons. Military physical education instructors / teachers must be physically trained and extremely skilled in demonstrating and putting into practice the technical elements. Confidence, enthusiasm and assessment oftechnical skills are essential to succeed in teaching hand-tohand combat techniques. The military instructor's assistants (sports or military instructors designated by him to assist him in the instructive-educational process) must also be properly trained to participate in the supervision and demonstration of technical procedures. Given these aspects, the selection of sports instructors is a first step in establishing an effective training program.

In order to perfect the different hand-to-hand techniques, it is necessary to make an uninterrupted effort, to reach the instinctive application of the movements and to teach others how to execute them safely. The following responsibilities of military physical education instructors/teachers are the core of the planning and execution of training for the formation of hand-to-hand combat skills with or without portable armament:

- achieve maximum efficiency with minimal effort, working continuously to reduce unnecessary explanations, movements and activities. Training must be simplified without compromising its content, efficiency or safety;

- to increase the level of sportsmanship by developing mobility and flexibility, as well as by controlling and managing stress;
- reinforce the details of each technique and provide constructive feedback (justified and anchored in a certain context), using occasional humor to motivate the military, but avoiding denigrating or offending them;

- to ensure that the materials used for training are present in sufficient quantities for all military personnel, that the training areas are well maintained and that there are no dangers of injury;

- prepare theoretically and practically before all training sessions, conducting training sessions of at least four hours per week, in order to maintain a high level of qualification;

- to train a competent sports instructor among the military (for each platoon level subunit) and to encourage their training, even outside of working hours;

- to improve the performance of the military, providing clear directions of work;

- to require all military personnel to observe strict discipline.

The safety of the military must be the main concern of the military physical education instructor / teacher and his / her assistants. In this regard, the best safety measures are constant checking and surveillance. In order to prevent injury to the military, the military physical education instructor / teacher should consider and process the following safety measures for all military personnel before conducting specific hand-to-hand combat training with or without portable armament, as follows:

- all practical training sessions must be closely and constantly monitored; so never leave a group unattended;

- systematically acquaint the military with each procedure through a complete explanation and demonstration before they attempt the movements;

- do not allow the military to exceed their duties or violate the instructions received;

- during the stages of learning or improving certain combinations of technical procedures, the training partner must not resist, in order to allow their correct assimilation by the practitioner;

- ensuring an adequate space between the military during all practical works (at least 9 meters $^{2}$ is recommended for each pair of military);

- checking the soldiers for emptying their pockets, removing all jewelry and personal identification ${ }^{6}$, before training begins; 
- blows to vital points (such as: head, neck or groin area) should only be simulated, not executed. The military may use light blows on other vulnerable areas (such as the abdominal area), but must be careful at all times during the execution;

- the military must know how the physical touches are performed and what are the verbal signals to indicate to the partner when to stop performing certain technical combat procedures (strangulation, dislocation, fixation, etc.);

- the military must perform the warm-up program and stretching exercises at the beginning of the practical sessions;

- learning and practicing falls will be done before making the designs or reaping;

- in order to avoid injuries, the soldier to be disarmed must not keep his finger inside the trigger guard;

- when practicing the procedures for disarming the opponent who attacks with the bayonet, the military must keep it in its holster (whether or not it is mounted on the weapon) or use rubber bayonets;

- the surface where the workouts are carried out must have a safety buffer zone, of at least 3 meters from the surrounding walls or objects, in particular for workouts involving throwing or fighting on the ground. It must be inspected for any foreign objects that may cause injury;

- putting and removing the bayonet is performed only at the command of the activity leader;

- weapons and materials should be placed on the ground when the military is given explanations or demonstrations;

- the training area should be a flat surface that does not become slippery when wet;

- left-handed soldiers should be put to work with each other to prevent injuries when certain complex movements are performed;

- when the weather is bad, gloves should be worn in combat training attire.

An advantage of specific hand-to-hand combat training with or without the portable armament provided is that they can be performed almost anywhere, with little preparation of the training area. A flat, grassy field, in the open air, without obstacles on it, is suitable for these training sessions. The instructors will use as working groups the pairs of two soldiers, established according to their height and weight, who will be positioned face to face and who will keep a minimum distance of 3 meters from the other groups.

The bayonet assault procedures offer the commander a unique training opportunity, allowing the military to put into practice the motor skills of handling the portable armament in the conditions of a simulated fight. To increase realism, it is recommended to create a fighting atmosphere by using pyrotechnic effects and by simulating the real sounds of war. The training objectives of bayonet assault procedures include:

- consolidation / improvement of hand-to-hand combat skills with or without portable armament;

- developing the capacity to act in complex conditions of effort with the application of procedures and counter-procedures specific to attack and self-defence;

- increasing the level of physical training of the military as a result of the aggressive execution of technical procedures;

- developing strength, speed, coordination and accuracy;

- carrying out realistic physical confrontations, in conditions similar to those encountered on a battlefield, using the portable weapons provided;

- the development of the will and the increase of the psychic resistance to the military, necessary aspects in a hand-to-hand combat;

- providing opportunities for subunit commanders to develop their own command, command and control system.

Before starting training, the military must be prepared for the physical demand that will follow. In this sense, the execution of a warm-up program will gradually increase the heart rate and internal body temperature, and stretching will prepare the ligaments and tendons for training, thus reducing the chances of injury. After this initial warmup, the simulation of movements in the technical procedures of hand-to-hand combat can be used to continue and diversify the warm-up. This allows the maximum use of training time, combining part of the warm-up with building muscle memory and perfecting basic techniques.

A well-executed demonstration of hand-tohand combat techniques by a professional teacher / instructor in the field is crucial for the military to succeed in learning, and unconvincingly presented movements can immediately destroy the credibility of the training. In this sense, in order to be effective, 
taking into account the size of the subunit to be trained, "the demonstration must be performed at the model level either by the specialist (also called direct demonstration ${ }^{7}$ ) or by another soldier from the training group, whose technical training allows it to do so (also called mediated demonstration ${ }^{8}$ )". 9

In order to show and explain a certain process, military physical education instructors / teachers must use a sequential demonstration, dividing the technical execution into several steps, so that the military can clearly see how the movement is performed from beginning to end. Sequential execution gives the military a way to observe the mechanics of each technical process. This teaching method allows the instructor to explain in detail what the sequence of movements is, while the instructor's assistants can move freely on the spot among the practicing military, intervening (if necessary) to correct execution errors.

When the instructor becomes confident that the soldiers who are being trained have become adept at sequentially performing a technical procedure, he must proceed to complete it. Gradually increasing the speed of execution to that used in combat (which does not always mean very fast), the military will notice how effective each technical procedure is. This will produce a sense of security that will allow them to develop a clear mental image of the principles behind the technique and give them confidence in their ability to apply technical procedures during a real confrontation.

Training pillows and personal protective equipment (helmet, waistcoat, shin guards, etc.) are recommended for use in training, as they protect training partners, even when the blows are performed with maximum force. Although blows are a very important part of a hand-to-hand fight, they are not the most effective way to end a fight. In training, instructors should encourage the aggressive spirit of the military so that they feel the effectiveness of hitting techniques and develop their hitting strength.

During hand-to-hand training, the leaders of the activity must maintain control throughout it. It is very easy for an unruly soldier to go beyond the regulatory limits imposed, especially when he becomes frustrated by his poor training. Therefore, it is recommended that he knows what is expected of him and what the repercussions are for committing inappropriate actions. In this sense, the most important control measure that a business leader can have after starting the training program is a means to stop the action (this can be a simple whistle, whose audible signals must be clear and easy to be heard by all the military).

\section{Basic hand-to-hand combat techniques with and without portable weapons}

Basic hand-to-hand combat techniques with and without portable armament can be classified into the following five broad categories: ground combat, grounding, striking, weapon handling, and dominant position control.

The basic techniques of ground fighting are built on a fundamental understanding of the dominant body position, which should be the main goal of most specific training, before moving on to the more difficult techniques of sitting. On the ground it is the place where the technique can be most easily used, not taking into account too much the size and strength of the opponent.

Before applying any disarmament or killing technique, the soldier must first gain and maintain a dominant body position, which will allow him to defeat an opponent stronger than himself. To become a competent fighter, it is fundamental to always appreciate what this dominant position in combat is, because it depends on the many technical combat procedures existing in martial arts. If a decisive attack technique is performed from a dominant position and fails, the military can simply try again, and if it is performed from a position other than the dominant one and fails, this will usually mean defeat.

Dominant body positions will be learned / consolidated / perfected on the ground, in order and according to priority, these being encountered in the technical procedures of immobilization (fixing) and strangulation most used in martial arts. In order to better understand these procedures, at this stage they are mastered as well the ways out of an immobilization or strangulation and the movements that lead to the end of the fight (repeated blows in vital areas, dislocation of joints, etc.). After the military has advanced in acquiring the basic elements of ground combat, they will systematically teach other complex ground fighting techniques (possible combinations and chains with other known procedures), important in the training of competent fighters. 
Before learning the techniques of bringing the opponent to the ground, the military must know some basic rules to annihilate the shock caused by body contact with the ground, to have a "smart fall" (the impact with the ground to be minimized). Each fall that is repeated (forward, backward, sideways - left/right) is an opportunity for the training partner to perfect various grounding procedures. These elements must always be "refreshed" before training, which is easily done by introducing them into the sequence of preparation of the body for effort.

In order to have control of a fight you have to control the distance between you and your opponent, this being much more dangerous when he is at a distance. Therefore, the goal in a confrontation is to avoid this interval, and when you train, the main goal should be to instill the courage to reduce this distance to take a convenient grip or to hit the opponent. Most ways of taking the ground involve making shots on the opponent, these being included in competitive fighting techniques in various styles of martial arts, but in a real fight, all of them know no bounds (throwing, harvesting, overturning, etc.). If you have difficulty gaining control over the enemy, a good technique is to push him back against a wall first.

In most cases, blows to the arm or foot are not an effective way to quickly end a fight (except for those applied to vulnerable points of the body). However, they are encountered in most hand-to-hand combat, and the military must know and master the optimal distance from the opponent ("refers to the approach required for the most effective use of a technique, executed at the correct angle of impact with target area" $)^{10}$. It is important to remember that, while you are in the opponent's range, you are prone to a counterattack on his part.

The key to developing effective hitting skills is to understand the optimal distance that is recommended to be taken from an opponent, knowing the effective techniques based on this distance and controlling the transition between various intervals. The technical procedures will be taught individually, even if they will almost never be used in this way. They must be approached as part of an ensemble (as part of a general combat strategy), taking into account that an effective hit is not something that can be taught / learned overnight.
Arm strokes (with the fist or elbow) must be performed in combinations to be effective and must be practiced to become automatic, especially in the stress of a fight. Particular attention should be paid to withdrawing the arm after each shot, always reaching a defensive position, as the opponent can counterattack at any time. During hand-to-hand combat, the simplest and most effective kicks are the low ones, as the military is usually burdened with boots and combat equipment. The degrees of joint mobility and muscle flexibility of the military are usually low during a hand-to-hand combat with an opponent, being subjected to additional high stress. Therefore, they need to rely on raw motor skills and strokes that do not require complicated movements or much prior training.

Effective handling of portable weapons can provide a significant advantage during a fight. For the military to be well trained in their use there must be connectivity between strengthening the technical procedures of armed and unarmed combat. As the military progresses in the training program, the portable handgun combat techniques must merge with the other technical elements of hand-to-hand combat learned, producing a fighter capable of performing a range of technical and tactical combinations.

In most combat situations, the individual weapons and hand grenades are the only weapons a soldier has at hand. In any case, in some scenarios, the military must fight the enemy in narrow areas (trenches), closed spaces (building rooms) or in places where they are present and non-combatants. In these situations, when you run out of ammunition or do not have time to reload the weapon, the bayonet can be the ideal weapon to capture the enemy. The military must immediately and instinctively use appropriate technical procedures, depending on the situation and the weapons at hand.

The principles used in skirmish combat with the portable armament provided (usually the submachine gun with bayonet-dagger mounted) are similar to the principles of knife fighting, using the same angles of attack and similar body movements. The principles of synchronization and distance remain paramount, the main difference being the greater distance provided by the length of the weapon. It is necessary for the soldier to fight hand-to-hand with the portable armament provided, using the biomechanics of his whole body (not 
just the upper train) encountered in all technical procedures and to develop the mental attitude that he will survive the fight. He must constantly evaluate every moment of a fight to determine his options and advantages/disadvantages over his opponent.

Even if the equipment is always improved and the combat tactics is constantly revised, the firepower only will not always be enough to annihilate the enemy. He will often remain in his place of defence until he is determined to engage by force in a close, skirmish battle. The role of the military, especially in the final phase of the assault, remains relatively unchanged. Its mission is to get closer to the enemy's position and get him out of the fight, this being the ultimate goal of any individual training. The handling of portable weapons during hand-to-hand combat is one of the final means in the action taken in an assault to defeat an opponent.

The bayonet is a weapon available to any soldier, being silent and recommended for use during infiltration missions at night when silence must be maintained or when the situation does not allow loading or reloading the pistol (lack of ammunition or blocking the weapon). Despite the limitations, the bayonet has many other noncombat utilitarian uses (sounding mines, cutting vegetation or wires, etc.), and is a means of training to raise the morale of combatants and increase the aggressiveness of fighters.

Tobecomeagoodfighterwith portableweapons, a soldier must be in very good physical and mental shape. A well-designed physical training program will increase the military's chances of surviving a skirmish with an opponent. Improving mental alertness will increase the ability to quickly detect and repel an opponent's attack, no matter which direction it comes from. Traits such as aggression, accuracy, balance and speed are essential in both training and real fighting situations. They will develop the confidence, coordination, strength and resilience of the military, qualities that a fighter with portable weapons must have. Hand-to-hand combat techniques can undergo slight technical changes depending on the morph functional features of the human body, as long as they become more efficient.

The bayonet (held in the hand or mounted on a weapon) is an effective weapon ifused aggressively; any hesitation in its handling can mean death. The soldier must attack the opponent in a constant assault, until he is eliminated or disarmed and captured. At the same time, he must be careful to take advantage of any area of the opponent's body left uncovered. If there are no such areas, the military must create one using counterattack procedures, respecting the following principles:

- the attack must be made on the vulnerable points of the body (face, neck, chest, abdomen or groin area);

- both in training sessions and in a real fight, the soldier who uses a bayonet weapon must use an aggressive battle cry; it will instill a sense of confidence in one's own abilities and will intimidate the opponent;

- the ability to fight instinctively using a bayonet weapon is formed to capitalize on the agility and combat technique of the soldier (precisely learned movements should not be a stress factor during training).

Hand-to-hand combat with the portable armament provided is learned in the following sequence: attack (guard) and relaxation (rest) positions, movements (forward/backward step, forward / backward jump), turns (change of front), stabbings, blows, defences and disarmament; and as the procedures are mastered, they will be combined into complex exercises. ${ }^{11}$

In order to survive in battle, the military must be able to cope with any unforeseen situation. Their ability to use any nearby object to be transformed into a weapon, in a situation of life and death, is limited only by their ingenuity and inventiveness. The following materials that are accessible to most soldiers can become weapons for attack, counterattack or defence against an opponent: small infantry shovel, Kevlar helmet, radio antennas, pens / pencils, various ropes, sticks, stones, sand or liquids thrown in the eyes of the enemy, etc.

A soldier cannot rely on the fact that every physical confrontation with an opponent will start from a dominant position. Therefore, in order to survive, he must master the basic techniques of getting out of a deficient position, followed by taking control of his battle plan. When an unarmed soldier faces an opponent armed with a knife, he must be mentally prepared for the likelihood of being severely cut, which is lower if the fighter is well trained in defending against knife attacks. 
Most hand-to-hand combat on the battlefield will involve more fighters, and whether there are more comrades or enemies or whether some parties are armed or not, the military should fight according to a well-established plan and general strategy. The fundamental truth of hand-to-hand combat is that the winner will always be the one whose comrades appear first with a weapon. Given the modern equipment that has emerged and the complicated tactical scenarios (and taking into account the two seconds available to make life and death decisions), the military must be permanently armed with practical and viable solutions.

The most common mistake when fighting and being part of a team is to get into a confrontation without having devised a tactical plan. Failure to do so will result in uncoordinated actions, and teamwork will often fail. Only through practice will the military be given the necessary confidence (in themselves and in their colleagues) and will the ability to think and act together be developed, under the conditions of stress during a hand-to-hand fight with opponents.

\section{Conclusions}

In order to achieve their objectives, hand-tohand combat training sessions with or without portable armament must be included in a complex training program. The proper choice and implementation of the mastered technical procedures must be instinctual, which can only be achieved by integrating hand-to-hand combat into a scenario. The process of developing the scenario is a difficult and demanding one, the military having to be aware of the fact that the war is hard, and the reality of training for war is just as harsh.

Training the military in the proper use of skirmish techniques involves detailed planning of training sessions by a military physical education specialist, as the risk of accidents must be mitigated by controlling both the scenario and the conduct of the exercise itself. When planning a scenario that includes hand-to-hand combat with or without the portable armament provided, several factors must be taken into account. A detailed and wellthought-out scenario will tell the military what type of technical procedures are most appropriate, depending on the mission to be performed. It must be explained to the military in detail (the events leading up to the scenario, as well as the immediate tactical situation) so that the appropriate motor actions come naturally from them, respecting the rules of engagement that give the military a clear understanding of the appropriate actions.

Every military man should have theoretical knowledge and motor skills on technical hand-tohand combat procedures with or without portable armament, as a situation can change in a split second. Skirmish combat is common in contemporary military operations, which justifies the priority in training these skills in the military. They will be used in a variety of tactical environments, providing an excellent example of the need for military adaptability in modern warfare.

\section{NOTES:}

1 In martial arts, body and spirit are never considered separate, but viewed as two inseparable elements in the perfection of Kai Chi Do (movement meditation).

2 Peter R. Jensen, Hand-to-Hand Combat and the Use of Combatives Skills: An Analysis of United States Army Post-Combat Surveys from 2004-2008, Center for Enhanced Performance, United States Military Academy, 2014.

3 https://urbansurvivalsite.com/weapons-of-opportuni ty-use-everyday-objects-self-defence, accessed on 08.03.2021.

4 D. Masciotra, E. Ackermann \& WM. Roth, "Maai": The Art of Distancing in Karate-Do Mutual Attunement in Close Encounters, Journal of Adult Development, no 8 / 2001, pp. 119-132.

5 [Headquarters, Department of the Army], Combatives, Field Manual No. FM 3-25.150, Washington DC, 2009, p. 21.

6 https://lege5.ro/gratuit/gmztkojsgy/semnul-personalde-identitate-regulament? $\mathrm{dp}=$ gyzteojrgq4do, accessed on 12.03.2021.

7 When the subunit is the size of a platoon or smaller.

8 When the subunit is the size of a company or larger.

9 G.C. Ciapa, Romanian Army servicemen's physical training in modern conflict, "Carol I" National Defence University Publishing House, Bucharest, 2018, p. 80.

10 https://frkt.ro/resurse/arbitru-de-karate-shotokankumite-rules, accessed on 29.03.2021.

11 Regulation of military physical education, Publishing House of the Technical-Editorial Center of the Army, Bucharest, 2013, art. 57.

\section{REFERENCES}

*** Regulation of military physical education, Publishing House of the Technical-Editorial Center of the Army, Bucharest, 2013.

[Headquarters, Department of the Army], Combatives, Field Manual No. FM 3-25.150, Washington DC, 2009. 
Andrei I., The importance of physical training in the military training process, "Carol I" National Defence University Publishing House, Bucharest, 2015.

Băițan G.F., Physical training of the Romanian Army soldiers in the context of NATO integration, "Carol I" National Defence University Publishing House, Bucharest, 2019.

Ciapa G.C., Physical training of the Romanian Army soldiers in modern conflicts, "Carol I" National Defence University Publishing House, Bucharest, 2018.

Dougherty M.J., Guide to Unarmed Special Forces for Skirmish Combat, Skirmish Combat Techniques from the Best Military Units in the World, MAST Publishing, 2014.

Jensen Peter R. \& Wrisberg C.A.,"Performance under acute stress: A qualitative study of soldiers' experiences of hand-to-hand combat", International Journal of Stress Management, 21, 2014.

Jensen Peter R., Hand-to-Hand Combat and the Use of Combatives Skills: An Analysis of United States Army Post-Combat Surveys from 2004-2008, Center for Enhanced Performance, United States Military Academy, 2014.

Masciotra D., Ackermann E. \& Roth WM., "«Maai»: The Art of Distancing in Karate-Do Mutual Attunement in Close Encounters", Journal of Adult Development no. 8 / 2001.

Larsen M., Modern army combatives: battleproven techniques and training methods, El Segundo, CA: Cruz Bay Publishing, 2013.

https://lege5.ro/gratuit/gmztkojsgy/semnulpersonal-de-identitate-regulament? $\mathrm{dp}=$ gyzte ojrgq4do

https://frkt.ro/resurse/arbitru-de-karate-shoto kan-kumite-rules 